\title{
Framework to Enhance ERP Usability by Machine Learning Based Requirements Prioritization
}

\author{
Shamaila Qayyum ${ }^{1 *}$, Almas Abbasi² \\ ${ }^{1}$ National University of Modern Languages, Department of Computer Science, Islamabad, Pakistan. \\ 2 International Islamic University, Department of Computer Science and Software Engineering, Islamabad, \\ Pakistan.
}

* Corresponding author. Tel: (92)3215475507; email: shamaillla@gmail.com; dralmas.iiurm@gmail.com Manuscript submitted December 1, 2016; accepted January 12, 2017.

doi: 10.17706/jsw.12.8.664-670

\begin{abstract}
With the growing trend of technology and increased business needs, Enterprise Resource Planning (ERP) systems are verily adapted by many organizations. Despite all the promising benefits and use, ERPs cannot always be successful. It has been established that ERP's success is measured in terms of its' users' satisfaction. Different models exist, that show how Information systems' success can be achieved. This paper focuses on the idea that machine learning helps in flawless prioritization of requirements and thus results in high user satisfaction. The paper proposes an IS success framework that incorporates machine learning based requirements prioritization techniques in order to increase users' satisfaction for making an ERP, a successful project.
\end{abstract}

Key words: ERP, Machine Learning, Requirements Prioritization, User Satisfaction

\section{Introduction}

\subsection{Background}

ERPs are the most widely used large-scale information systems adapted by organizations, as they are cost effective and well performed [1], [2] ERP can be defined as a system that integrates different departments and gives solutions by providing interface to different corporate functions. However, ERP's are not always successful. In order to evaluate the success/failure of an ERP, it is first required to establish the context in which ERP's success is to be measured [3]. Literature provides us with different success measures of ERP through different perspective [4]. The ERP's are not always able to provide the expected outcomes and one of the reasons being noted is lack of user involvement [2]. Most of the studies asserted that in order to define an ERP, a success, its users must be satisfied with it [5]. There are various factors that affect the satisfaction level of user [6] [7]. Asserted that user involvement is one of the factors affecting the user satisfaction. To make a software successful from users' perspective, it must comply fully to users' needs [8]. To achieve this, the requirements are supposed to be properly elicited from the stakeholders and prioritized according to stakeholders' precedence [9]-[11]. It means, identifying which requirements are more important for the stakeholder [12]. It helps analyst in preparing a development plan that comply the stakeholders' need [8]. However, requirements prioritization is a trivial process and becomes more challenging with the increase in number of requirements [13]. Lately it has been observed that machine learning is used in the requirements prioritization process to prioritize requirements in a consistent way. 
The learning algorithms learn the ranks of requirements and can prioritize the requirements for the similar projects in future [14] [15].

In our study we intend to find the requirement prioritization techniques using machine learning and understand if there is any technique that is better used for ERP. We then aim to provide a framework for ERP implementation that incorporates machine learning in requirements engineering and prioritization approaches and understand how this framework helps in enhancing the user satisfaction of ERP.

\section{Literature Review}

This section provides a detailed review on ERP systems, their evaluation and success. The next section of the literature review presents a brief description about the machine learning approaches used in software engineering and particularly in requirements prioritization.

\subsection{ERP Systems}

ERP systems are the large scale information systems for an organization, having a single database which several departments use simultaneously and share the information [16]. ERP's are used to gain various organizational benefits such as reduced operational costs, better decision making, business growth, flexible infrastructure and other organizational benefits [17]. However the ERP is not always a success and it is very important for an organization to have a successful implementation of ERPs, as the ERPs promise many organizational benefits [18]-[20]. asserted that in order to evaluate an information system, one must follow some strategic approach. It is mandatory to identify first that in which context success of ERP is supposed to be measured [3]. From literature we can find some effective approaches for evaluation of Information system success. In order for an ERP to be successful, it must meet the stated objectives, should be developed within time and budget, its user must be happy with it and the software must fulfill their expectations [21]. From the literature it is found that "user satisfaction" is one of the widely used measures for evaluating information systems success [5]. Hence to study the success of software their user satisfaction level should be identified [22]. The user satisfaction is the extent to which the software meets users' requirements [23]. End user satisfaction depends on how much the system is according to their expectations [24].

\subsection{Requirements Prioritization with Machine Learning}

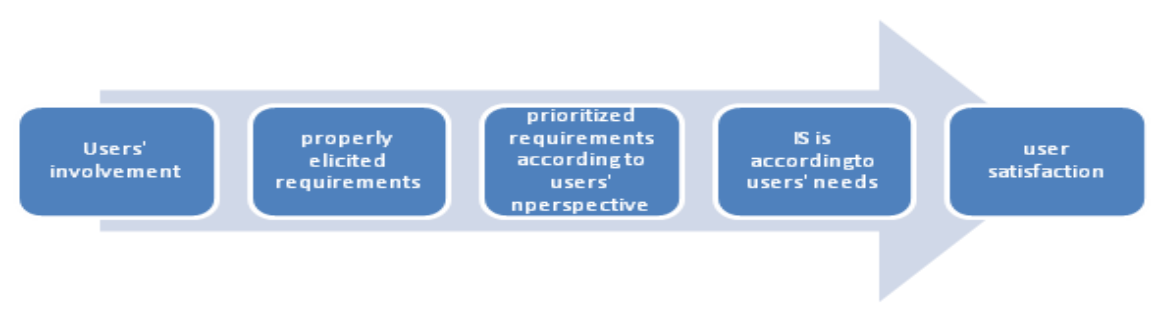

Fig. 1. Relationship between users' involvement and users' satisfaction.

For software to be acceptable by a user, it must be according to user's requirements [9]-[11]. Requirements of the users must be assigned some priorities based on their importance in the system-to-be [25]. Software Requirements Prioritization process deals with identifying the important requirements from the perspective of various stakeholders [12]. It is vital so that the important requirements of stakeholders are incorporated into the system within budget and time constraints [26] [27]. This also helps in planning various iterations of software development, where the software is deployed in many incremental phases. Software engineers can easily place the most important, risky requirements in first place once they know the priorities of the requirements [28].Requirements prioritization process requires stakeholders to compare the requirements and assign ranks to them [29], however as the number of requirements tend to 
increase, this comparison becomes more complex [13].

To help reduce the effort of these trivial tasks of requirements engineering, researchers have provided some machine learning approaches merged with the domain of requirements engineering. They help in reducing the human efforts of eliciting knowledge and perspective of users during Requirements Engineering Process [30]-[32]. Some researchers have also found the importance of machine learning and proposed a framework for solving requirements prioritization problems using the said approach [33] [34]. [14] [15] have proposed machine learning approaches for requirements prioritization. The process rely on a generic set of activities in which requirements are elicited, the ranks to each requirements is assigned by the stakeholder. The machine learning algorithm applied learns these ranks for further use. Requirements can be ranked by doing pair wise comparisons by stakeholders [14] [15]. However, literature lacks any research that shows how these machine learning based approaches are helpful while considering the large scale Information systems, i.e. ERPs.

\section{Methodology}

In our study we propose a framework that helps in increasing the usability of ERPs. The framework is basically enhancement of the updated usability framework proposed by [35]. According to this model the net benefits of an organization are achieved in the form of organizational benefits. Net benefits are actually the organizational impact achieved with the use of information systems. The D\&M model [35] clearly shows that in order for an organization to get benefit from an ERP, the system must be useful for the users and they should be satisfied while using it. According to updated D\&M IS success model factors that affect systems usability and users' satisfaction are: information quality, system quality and service quality.

\subsection{Our Approach}

We propose a framework that adopts the updated D\&M IS success model by [35]. The difference between our approach and that of [35] is that according to them, quality of system, information and service contribute to the satisfaction of users, however, a qualitative review of literature has shown that users involvement is necessary for users' satisfaction [7]. Users' involvement helps in understanding the view of the users. For a software to be satisfactory for user, it must achieves users' purpose by fulfilling his needs [8]. In order to achieve users' satisfaction and understand his needs, [9]-[11]. asserted that proper elicitation of requirements from stakeholders must be done. This should be accompanied with the prioritization of these requirements according to their precedence. Requirements prioritization means understanding which requirements are important for stakeholders [12]. This relationship between user involvement and user satisfaction has been shown in Fig. 1.

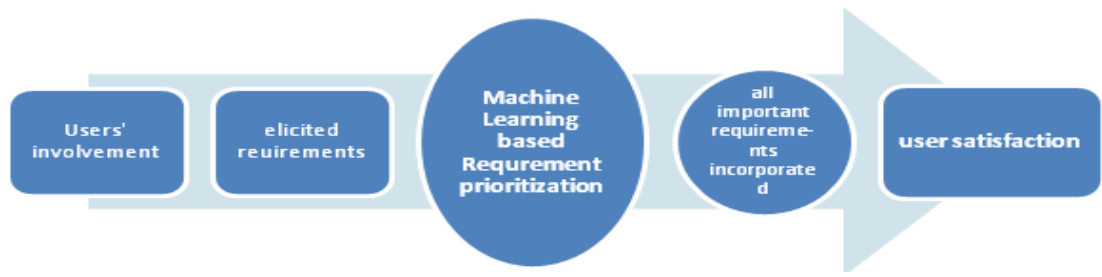

Fig. 2. Updated relationship between users' involvement and users' satisfaction.

Although, requirement prioritization is a very complex task specially when there is an increase in number of requirements [13]. It has been learnt from the literature that machine learning has been used in requirements prioritization process for a consistent and easy ranking of requirements. The algorithms used in these machine learning techniques not only learn the ranks of the requirements, but are capable of learning the ranking policies too and further ranking the requirements by themselves [14], [15]. Keeping in mind that ERPs are large scale Information Systems, having many departments [36], many stakeholders are 
associated with it. Having so many stakeholders increases the number of requirements and the priorities of various stakeholders are different. Having a large amount of requirements from different stakeholders of various backgrounds and functional areas makes the requirements prioritization task even more complex. We assume that machine learning can help reducing the effort of requirements prioritization for large scale information systems i.e. ERP. With this view point, we update the relationship shown in Fig. 1, by incorporating machine learning based requirement prioritization. The updated relationship between users' involvement and users' satisfaction is shown in Fig. 2.

\subsection{The Proposed Model}

Based upon the above discussion we have proposed a framework for enhanced usability of ERP systems. This framework is originally adopted by the model presented by [35]. The model is updated according to our discussion from section 3.1 and the relationships of the constructs shown in Fig. 2. The model proposed by this study for enhanced usability of ERP systems by incorporating ML based RP techniques for ERPs, is shown in Fig. 3.

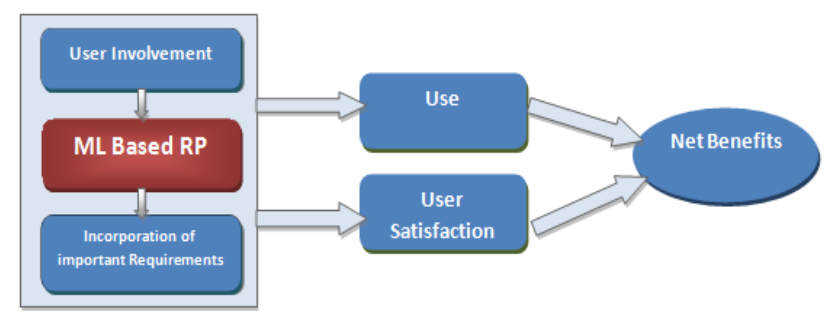

Fig. 3. Proposed framework for enhanced ERP usability by incorporating ML based RP techniques.

The framework proposes a systematic approach to be followed for the implementation of an ERP, to make it a successful project. According to this, the users involvement should be assured while considering to deploy any ERP, as stated by [7]. After the careful elicitation of requirements from the stakeholders', their requirements are prioritized using Machine Learning Based Requirement Prioritization Techniques. Requirements prioritization is necessary as we deal with multiple stakeholders and their requirements may vary in terms of precedence and importance. Once the requirements are prioritized and incorporated accordingly, the system built will be according to the requirements of the users. As [37] asserted that a system fulfilling users' needs, makes its users satisfied. And the satisfied users, properly using the ERP ,eventually help the organization achieving different benefits from ERP [35]-[38].

Machine Learning algorithms learn the ranks of requirements and can further assign ranks to similar requirements themselves. This is an additional benefit through which a lot of time and effort can be saved for the future projects having same kind of requirements.

\subsection{Comparison of Proposed Model with the Previous One}

The previous model presented by [35] presented that satisfaction of an IS user can be achieved if the system exhibits a few constraints; system quality, information quality and service quality. User satisfaction contributes to the net benefits of an organization that it gains from the use of an information system. This is very true, however it is well established that a user can be satisfied with the system only when the system is according to his/her requirements [5], [21]-[24], [39]. In this study, we focused on the importance of users' involvement while developing software, so that their needs are elicited and prioritized properly and the system is built according to their needs. Requirements can be prioritized well using machine learning techniques. This relationship of user involvement and user satisfaction via ML based RP techniques, is 
shown in Fig. 2. On the basis of this relationship the previous model is updated as shown in Fig. 3. This clearly shows that in order to gain users' satisfaction, it is not enough that system provides quality of information and services, but it should be according to the prioritized requirements of stakeholders.

\section{Limitations and Future Work}

The validity of any proposed framework can only be proven with its empirical evaluation. This paper lacks the empirical evaluation of the proposed framework owing to time and resource constraints. In the further task, this framework can be tested empirically to prove whether it achieves its promised assumption of enhancing the usability of ERP by using machine learning based requirements prioritization techniques or not. Moreover, machine learning based requirements prioritization technique for large scale software systems can also be proposed that may be used within this framework.

\section{Conclusion}

In this paper we have proposed a framework for enhancing the usability of ERP systems by increasing the satisfaction of users. The framework is basically inspired by the D\&M IS success model with some variations. In order to increase the satisfaction of users, the system must fulfill their requirements. To achieve this, our proposed framework asserts that, users should be involved during the development phase of ERP. Users' requirements are elicited and prioritized. For prioritization of requirements, Machine Learning based Requirements Prioritization techniques are used according to the proposed framework. ML based RP techniques not only help in prioritizing requirements in an efficient way but also prioritize the requirements for future similar projects, based on the ranks they have learned from the past ones. This helps in reducing time and effort for the implementation of these large scale projects and makes them more user satisfactory by meeting their needs.

\section{References}

[1] Tsai, W. H., Chen, S. P., Hwang, E. T., \& Hsu, J. L. (2010). A study of the impact of business process on the ERP system effectiveness. International Journal of Business and Management, 5(26).

[2] Abugabah, A., Sanzogni, L., \& Poropat, A. E. (2009). The impact of information systems on user performance: A critical review and theoretical model. In International Conference on Information Systems (ICIS).

[3] Farby, B., Land, F., \& Target, D. (1993). How to assess your IT investment. ed: Oxford: Butterworth Heinemann.

[4] Chen, S. G., \& Lin, Y. K. (2008). An evaluation method for enterprise resource planning systems. Journal of the Operations Research Society of Japan, 51, 299-309.

[5] Wei, C. C., Liou, T. S., \& Lee, K. L. (2008). An ERP performance measurement framework using a fuzzy integral approach. Journal of Manufacturing Technology Management, 19, 607-626.

[6] Calisir, F., \& Calisir, F. (2004). The relation of interface usability characteristics, perceived usefulness, and perceived ease of use to end-user satisfaction with enterprise resource planning (ERP) systems. Computers in Human Behavior, 20, 505-515.

[7] Mahmood, M. A., Burn, J. M., Gemoets, L. A., \& Jacquez, C. (2000). Ariables affecting information technology end-user satisfaction: A meta-analysis of the empirical literature. International Journal of Human-Computer Studies, 52, 751-771.

[8] Leffingwell, D., \& Widrig, D. (2000). Managing Software Requirements: A Unified Approach. AddisonWesley Professional.

[9] Davis, A. M. (2003). The art of requirements triage. Computer, 36, 42-49. 
[10] Mead, N. (2006). Requirements Prioritization Introduction. Software Engineering Institute Web Publication, ed: Carnegie Mellon University, Pittsburgh.

[11] Perini, A., Susi, A., Ricca, \& F., Bazzanella, C. (2007). An empirical study to compare the accuracy of AHP and CBRanking techniques for requirements prioritization. Comparative Evaluation in Requirements Engineering.

[12] Ruhe, G., Eberlein, A., Pfahl, D. (2003). Trade-off analysis for requirements selection. International Journal of Software Engineering and Knowledge Engineering, 13, 345-366.

[13] Kassel, N. W., \& Malloy, B. A. (2003). An approach to automate requirements elicitation and specification. Proceedings of the 7th International Conference on Software Engineering and Applications (pp. 3-5).

[14] Singh, D., \& Sharma, A. (2014). Software requirement prioritization using machine learning.

[15] Perini, A., Susi, A., \& Avesani, P. (2013). A machine learning approach to software requirements prioritization.IEEE Transactions on Software Engineering.

[16] Davenport, T. H. (2000). The future of enterprise system-enabled organizations. Information Systems Frontiers, 2, 163-180.

[17] Zeng, Y., Lu, Y., \& Skibniewski, M. (2012). Enterprise resource planning systems for project-based firms: benefits, costs \& implementation challenges. Journal for the Advancement of Performance Information \& Value, 4.

[18] Chao, P. G., \& Baptista, N. M. (2009). Surfacing ERP exploitation risks through a risk ontology. Industrial Management and Data Systems, 109, 926-942.

[19] Zhu, Y., Li, Y., Wang, W., \& Chen, J. (2010). What leads to post-implementation success of ERP? An empirical study of the Chinese retail industry. International Journal of Information Management, 30, 265-276.

[20] Jones, S. (2008). Social dimension of IT/IS evaluation: Views from the public sector, Evaluating Information Systems (p. 236).

[21] Al, M. M., Al, M. A., \& Zairi, M. (2003). Enterprise resource planning: A taxonomy of critical factors. European Journal of Operational Research, 146, 352-364.

[22] Wu, J. H., \& Wang, Y. M. (2007). Measuring ERP Success: The key-users' viewpoint of the ERP to produce a viable IS in the organization. Computers in Human Behavior, 23, 1582-1596.

[23] Wu, J. H., \& Wang, Y. M. (2006). Measuring ERP success: The ultimate users' view. International Journal of Operations \& Production Management, 26, 882-903.

[24] Venkatesh, V., \& Davis, F. D. (2000). A theoretical extension of the technology acceptance model: Four longitudinal field studies. Management Science, 46, 186-204.

[25] Berander, P. (2004). Prioritization of Stakeholder Needs in Software Engineering: Understanding and Evaluation.

[26] Finkelstein, A., Harman, M., Mansouri, S. A., Ren, J., \& Zhang, Y. (2009). A search based approach to fairness analysis in requirement assignments to aid negotiation, mediation and decision making. Requirements Engineering, 14, 231-245.

[27] Barney, S., Aurum, A., \& Wohlin, C. (2008). A product management challenge: Creating software product value through requirements selection. Journal of Systems Architecture, 54, 576-593.

[28] Berander, P., Khan, K. A., \& Lehtola, L. (2006). Towards a research framework on requirements prioritization. SERPS, 6, 18-19.

[29] Kobayashi, A., \& Maekawa, M. (2001). Need-based requirements change management. In Engineering of Computer Based Systems, 2001, ECBS 2001, Proceedings of the 8th Annual IEEE International Conference and Workshop on the, (pp. 171-178). 
[30] Sultanov, H. \& Hayes, J. H. (2013). Application of reinforcement learning to requirements engineering: requirements tracing. Proceedings of the 21st IEEE International Requirements Engineering Conference (RE), (pp. 52-61).

[31] Sandhu, G., Pal, S., \& Pal, P. Knowledge Extraction in Requirement Engineering with Machine Learning Perspective.

[32] Menzies, T., Kiper, J. D., \& Hu, Y. (2001). Machine learning for requirements engineering,. Submitted to ASE-2001.

[33] Avesani, P., Bazzanella, C., Perini, A., \& Susi, A. (2004). Supporting the requirements prioritization process. A Machine Learning Approach (pp. 306-311).

[34] Avesani, P., Bazzanella, C., Perini, A., \& Susi, A. (2005). Facing scalability issues in requirements prioritization with machine learning techniques. Proceedings of the 13th IEEE International Conference on Requirements Engineering (pp. 297-305).

[35] Delone, W. H., \& McLean, E. R. (2003). The DeLone and McLean model of information systems success: A ten-year update. Journal of management information systems, 19, 9-30.

[36] Sayegh, D. R. (2010). Factors affecting the implementation of ERP systems in organisations in the UAE, British University in Dubai.

[37] Al Mashari, M., \& Zairi, M. (2000). Information and business process equality: the case of SAP R/3 implementation. The Electronic Journal of Information Systems in Developing Countries, 2.

[38] Petter, S., DeLone, W., \& McLean, E. (2008). Measuring information systems success: models, dimensions, measures, and interrelationships. European Journal of Information Systems, 17, 236-263.

[39] Wang, X., \&Huang, J. (2006). The relationships between key stakeholders' project performance and project success: Perceptions of Chinese construction supervising engineers. International Journal of Project Management, 24, 253-260.

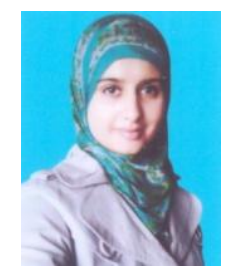

Shamaila Qayyum is a PhD scholar. She is pursuing her PHD in software engineering from International Islamic University, Islamabad, Pakistan. She is currently serving as a lecturer at Department of Computer Science in National University of Modern Languages, Islamabad, Pakistan. Her research interests are crowd sourcing, software engineering, requirements engineering, usability, ERP systems.

Almas Abbasi has received her PhD degree from University of Malaya in 2015. She is currently working as assistant professor at Faculty of Computer Science and Software Engineering, International Islamic University, Islamabad, Pakistan. Her research interests include data hiding, data security, machine learning, biometric security and mobile applications. 